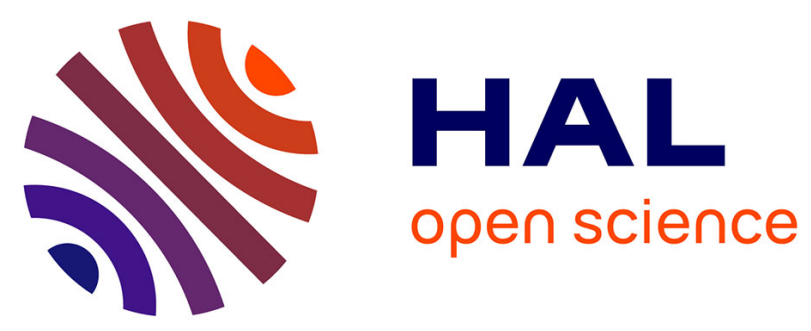

\title{
Open access and research dissemination in Africa
}

Katie Wilson, Anthony Kiuna, Richard Lamptey, Susan Veldsman, Lucy

Montgomery, Cameron Neylon, Richard Hosking, Karl Huang, Alkim Ozaygen

\section{To cite this version:}

Katie Wilson, Anthony Kiuna, Richard Lamptey, Susan Veldsman, Lucy Montgomery, et al.. Open access and research dissemination in Africa. ELPUB 2020 24rd edition of the International Conference on Electronic Publishing, Apr 2020, Doha, Qatar. 10.4000/proceedings.elpub.2020.20 . hal-02544891

\section{HAL Id: hal-02544891 \\ https://hal.science/hal-02544891}

Submitted on 16 Apr 2020

HAL is a multi-disciplinary open access archive for the deposit and dissemination of scientific research documents, whether they are published or not. The documents may come from teaching and research institutions in France or abroad, or from public or private research centers.
L'archive ouverte pluridisciplinaire HAL, est destinée au dépôt et à la diffusion de documents scientifiques de niveau recherche, publiés ou non, émanant des établissements d'enseignement et de recherche français ou étrangers, des laboratoires publics ou privés. 


\title{
Open access and research dissemination in Africa
}

\author{
Katie Wilson, Anthony Kiuna, Richard Lamptey, Susan Veldsman, Lucy \\ Montgomery, Cameron Neylon, Richard Hosking, Chun-Kai (Karl) Huang \\ and Alkim Ozaygen
}

\section{Key objectives of the study}

1 In this paper, we explore open access performance within Africa, and specifically in four African countries to understand the progress of higher education and research institutions towards openness. This includes contributions from Ghana, Rwanda and South Africa, investigating open research output and dissemination through repositories and open access published sources. Analysis of institutional policies and institutional repositories supporting the production of open, diverse and equitable knowledge provides context in the countries investigated. The study is significant in its use of a variety of sources to understand the open knowledge landscape in four African countries.

\section{Design and methodology}

2 The paper includes contributions from the Curtin Open Knowledge Initiative (COKI) and from experts in the field in Ghana, Rwanda and South Africa. To understand open access performance, COKI analyses institutional research output with DOIs from bibliographic databases Microsoft Academic, Scopus and the Web of Science. Crossref metadata for each DOI provides information on publication dates. DOIs are checked against Unpaywall to determine the open access status for institutional publications.

Contributions from Ghana, Rwanda and South Africa include background and firsthand experience regarding the current research dissemination landscape. COKI retrieved and analysed policies and statements, services and repositories from public 
websites and directories using a Jupyter notebook supported by a small library of Python code.

Manual searching and directory tools supplement the automated process to confirm the presence or absence of policies and repositories.

\section{Research output from Africa: Overview}

Research productivity from the African continent has increased over the last two decades, although this varies by country. However, analysis of research output is constrained by the dominance of the Global North in this sphere, and the limited inclusion of Global South sources in publication databases. This extends to world university rankings. Despite calls for a "tailored range of metrics" reflecting the different priorities and economies within Africa (Pretorius), the Times Higher Education Africa Rankings continue to rely solely on publication citation data and research productivity data from the Scopus publication database.

Bibliometric analysis by Sooryamoorthy of output from 51 African countries (consisting of articles and reviews in all languages indexed in the Web of Science (WoS) Science Citation Index Expanded database) published between 2000-2015, found South Africa (26\%) and Egypt (21\%) together produced almost half the 369,683 scientific publications over this time period. Tunisia (8\%), Nigeria (6\%), Morocco (6\%), Algeria (6\%) and Kenya (4\%) followed. The Nature Index, tracking output author affiliation data from research articles published in a selective set of 82 "high-quality science journals", found similar results for research output from 38 African countries in 2018. A more complex analysis of African output from 2002- 2011 employed the WoS InCites tool and normalised each country by GDP and population size (Confraria and Godinho). A similar result to Sooryamoorthy showed leading output from South Africa, Egypt, Tunisia, Nigeria, Morocco and Algeria, and noted growth in East African countries.

7 While these articles indicate growth in African published research, they present an incomplete account. Reliance on publication sources from the Global North preclude understanding the full output. The scope of sources used (Web of Science, Nature Index) is limited to selected journals primarily from the Global North and the English language. The coverage of African-based journals such as those in Africa Journals Online (AJOL) is limited. Further, the analyses do not include open access status of publications (WoS began to include Unpaywall OA data from 2017). Academic publication, citation and research metrics used by world ranking services to measure research excellence exclude much research undertaken in Africa that operates outside established structures and systems (Baker). Dennis Masaka emphasises the importance of "open production of knowledge" (360) from Africa as a precursor to recognising the epistemological denial and exploitation of indigenous knowledges from Africa. Locally conducted and produced research has valuable impact when shared with participants and within communities (Twine, Kahn and Hundt).

Chan (2018) refers to the impact of "epistemic injustice" in publishing practices and research evaluation standards imposed by the North on knowledge production and research dissemination in the Global South. Piron (124) identifies "cognitive injustice" in Africa, with international rankings and publishers placing pressure on institutions and researchers to comply with Western frameworks, language and expectations. This inhibits local research needs and values. Libraries subscribe to predetermined e- 
resource packages that exclude local research publication sources and knowledge. Such power imbalances make the case for institutional control of output through deposit in institutional repositories and institutional publishing to disseminate African research worldwide. Open access has the potential to expand the dissemination of African research through the inclusion of material in multiple languages, open journals and university presses (Piron). For example, Africa Journals Online, established in 1998, hosts 524 scholarly journals (262 open access) from 32 countries. AfricaArXiv Preprints provides a source for the distribution of preprints in multiple languages (Ahinon and Havemann).

COKI analysis of Green and Gold open access research output from selected institutions identifies strong performance for some African institutions (see Figure 1). While some institutions cluster by region, African institutions are more disparate as numbers increase, representing varied practices and policies across countries.

Figure 1: Global open access publications with DOIs (gold OA) versus repository-mediated open access (green OA) by institution for 2017.

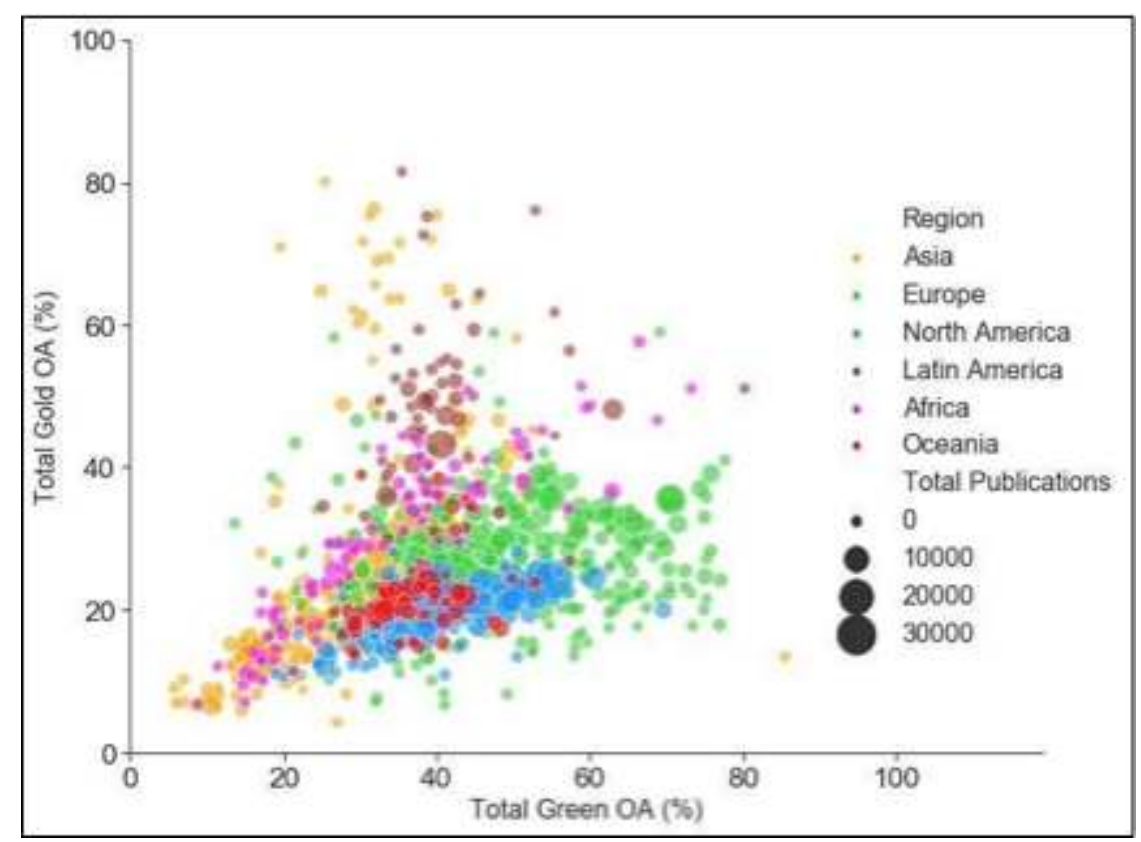

Each plotted point is a university, with size indicating the number of outputs analysed and colour showing the region. Articles can be open access through both publishing and repository routes so $x$ and y values do not sum to give total open access.

(Data sources: Microsoft Academic, Scopus, Web of Science, CrossRef, UnPaywall. Analysis and image: COKI, 2020)

Open access offers the means of disseminating research output to readers beyond the institutional subscription paywalls of electronic resources. For African countries, this enables sharing locally produced research, reducing dependence on and limited access to high cost journal subscriptions. Iyandemye and Thomas analysed open access biomedical research literature from PubMed and found publication to be higher in low income countries globally, indicating the value of open access as a means of dissemination. The costs of Gold open access with article processing charges (APCs) to publish in commercially based journals are out of reach for many researchers in the Global South. South African research institutions have raised concerns about the emphasis on Gold with high APCs in the European Union's cOAlitions Plan S, potentially 
limiting publication by African researchers (Paterson). However, as our analysis below shows, the rate of Gold open access publication is growing in Ghana, South Africa and Uganda. Locally published journals provide open access opportunities.

The African Academy of Sciences (AAS) is a non-profit, non-aligned organisation with aims to accelerate science research in Africa, based in Kenya. It is developing AAS Open Research, an open access based open peer-review platform to facilitate the dissemination of output from AAS funded research and affiliated researchers, "powered" by F1000 research (African Academy of Sciences). Teixeira Da Silva et al. note that AAS is supported by Elsevier, among other organisations. Elsevier also publishes the multidisciplinary journal Scientific African founded in 2018 by the Next Einstein Forum (NEF) and the African Institute of Mathematical Sciences. The journal is gold open access, with an article processing charge of USD200.

\section{Institutional repositories}

Institutional repositories play a major role for universities and research organisations in managing the archiving and dissemination of local research output (Kakai, Musoke, and Okello-Obura). The number of repositories across Africa is growing, although recorded numbers vary. The OpenDOAR directory (Jisc Services) includes 221 repositories in 24 countries, representing a small but steady annual growth (Morrison). The African Digital Research Repositories directory (International African Institute) identifies 177 known repositories in 26 countries. The Registry of Open Access Repositories (ROAR)(University of Southampton) includes 144 repositories in 21 countries.

However, details and links in these directories are not always current. Some repositories consist of a shell outline, with minimal deposits; some contain theses and dissertations only; and accessibility can be difficult and inconsistent. There is an acknowledged need for more resourcing, staff training in digital open access technologies including repository software, improved storage, electric power, internet access and greater awareness among research staff about the preservation and dissemination potential of IRs (Anyaoku, Echedom, and Baro; Bangani; Okorama; Piron). Internet access costs are high in developing countries and technology can be unreliable and open to misuse (Addo, Masaka).

\section{Open knowledge and research output}

This section explores national positions and analysis of open knowledge policies, institutional repositories and open access research output for Ghana, Rwanda, South Africa and Uganda.

\section{Ghana, West Africa}

Institutional repositories in Ghana began to be established 11 years ago. The International Network for the Availability of Scientific Publications (INASP) and the Consortium of Academic and Research Libraries in Ghana (CARLIGH) organised and funded IR workshops from 2008. Further workshops with the Association of African 
Universities (AAU) and the Database of African Theses and Dissertations (DATAD) project promoted access to research output. Creating awareness of the open access benefits among researchers and encouraging deposit in repositories has been a challenge (Lamptey and Corletey). Policies and mandates promoting open access and the deposit of research output in institutional repositories help create authority for repository managers, clarify copyright issues, and contribute to awareness among researchers (Martin-Yeboah, Alemna and Adjei).

16 To understand the current landscape in Ghana we analysed publicly available data for 21 higher education and research institutions: ten public universities identified by the Ghana National Council for Tertiary Education, seven private universities, three research institutes and one government organisation. Four public universities have publicly available policies and statements recommending open access publication or institutional repository deposit. Ten institutions have active repositories providing open access to research publications, conference proceedings, open access journals, theses and public documents. They are in six public universities, four private institutions, one research institute and one government body. Of the 204 tertiary institutions listed on the Ghana National Accreditation Board (NAB) website, nine have working, public institutional repositories. Five repositories are registered in the OpenDOAR website, with two listed in ROAR. Several institutions refer to the planning or development of repositories on websites and in strategic plan documents, but these were not active or accessible at the time of writing.

Two universities are signatories to the Berlin Open Access declaration (Max Planck Gesellschaft.). Evidence of funds to support the payment of processing charges to publish in open access sources was not identified.

Kwame Nkrumah University of Science is the first public university to have a repository. Its strategy to promote and populate the IR makes it compulsory for academic staff to archive their research publications in the university repository before they can submit their promotion dossier.

Table 1. Ghana - open access policies, Berlin declaration signatories, open access publishing funds, institutional repositories

\begin{tabular}{|l|l|l|l|l|l|}
\hline $\begin{array}{l}\text { Institution } \\
\text { type }\end{array}$ & $\begin{array}{l}\text { Number of } \\
\text { institutions }\end{array}$ & $\begin{array}{l}\text { OA } \\
\text { Policy }\end{array}$ & $\begin{array}{l}\text { Berlin } \\
\text { signatory }\end{array}$ & $\begin{array}{l}\text { Open access } \\
\text { funds }\end{array}$ & $\begin{array}{l}\text { Institutional } \\
\text { Repository }\end{array}$ \\
\hline Universities & 18 & 4 & 2 & 0 & 10 \\
\hline $\begin{array}{l}\text { Research } \\
\text { institutes }\end{array}$ & 2 & 0 & 0 & 0 & 1 \\
\hline $\begin{array}{l}\text { Government } \\
\text { body }\end{array}$ & 1 & 0 & 0 & 0 & 1 \\
\hline
\end{tabular}

19 Analysis of the open access status of research output from five public universities from 2000-2018 illustrates, in particular, the number of open access items overtaking items not available as open access since 2015 (see Figure 2). 
Figure 2: Research output for five Ghana public universities, 2000-2018: number of items with DOIs, open access and not open

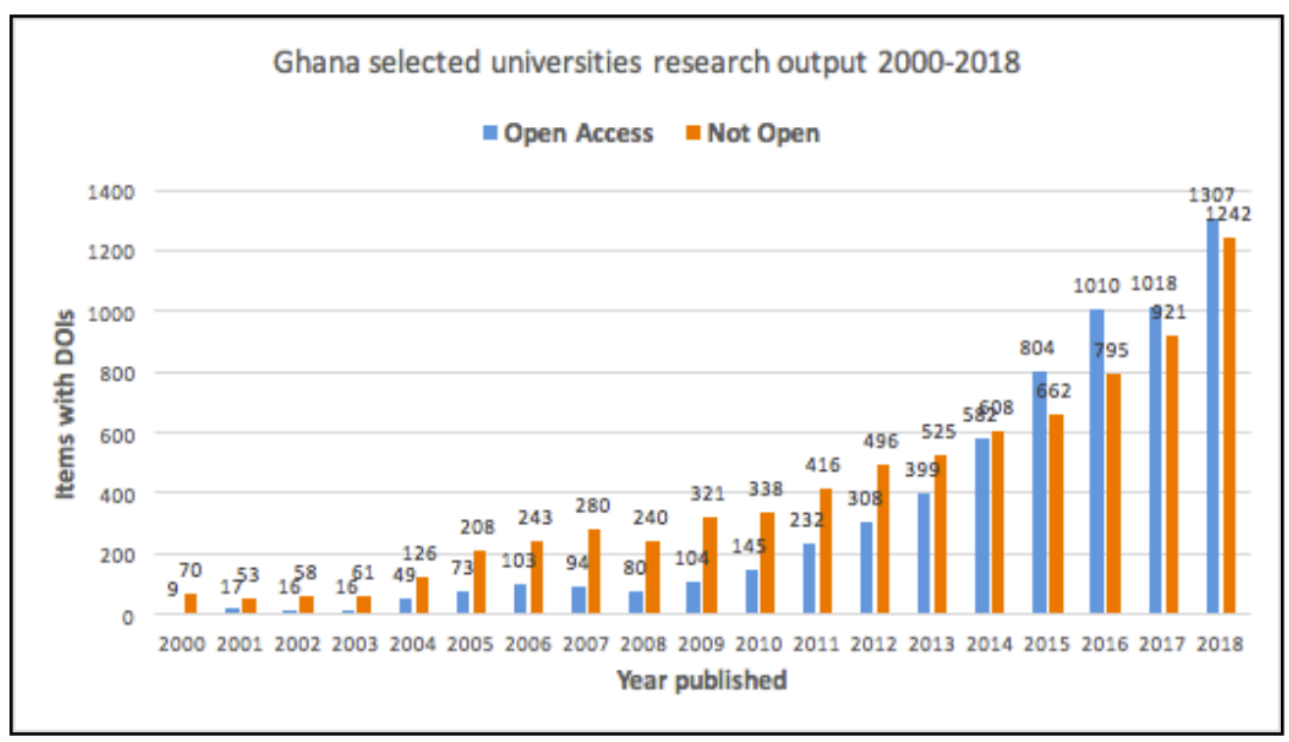

(Data sources: Microsoft Academic, Scopus, Web of Science Analysis and image, COKI, October 2019)

Analysis of percentages of open access types for the five public universities in Figure 3 shows growth in Green (repository deposit) was overtaken by Gold (in OA and hybrid journals) around 2011. The figures for Bronze OA (free to read on a publisher page, but without a license for reuse of reproduction) show a reduction from about 2006.

Figure 3: Five public universities, Ghana: percentages of open access research output (items with DOIs), 2000-2018

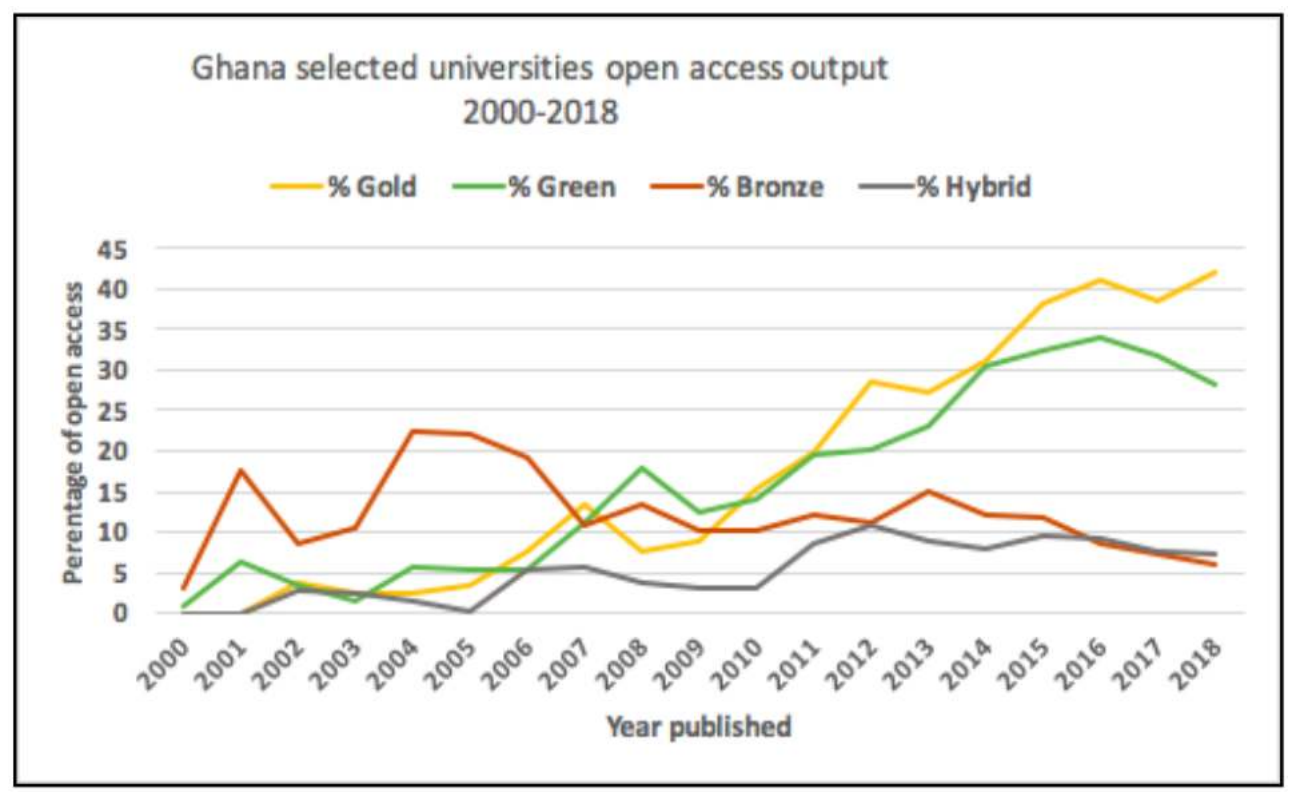

(Data sources: Microsoft Academic, Scopus, Web of Science. Analysis and image, COKI, October 2019)

Lower percentages exist for Hybrid OA (published in a subscription journal with a free license, and an article processing charge (APC) paid by authors) (Piwowar et al). Items 
can be Green at the same time as being available through Gold, Hybrid or Bronze (published) routes.

This analysis of open access research output since 2000 showing strong growth in green (deposits in repositories) and gold (published in OA journals and hybrid journals) highlights the impact of policies and institutional repositories, major funder policies and the proactive and supporting work of Electronic Information for Libraries (EIFL) in Ghana. EIFL has supported advocacy workshops on National Institutional Repository development and the establishment of Ghana Journals Online (GhanJOL). These activities and support have raised the number of open access items, overtaking items not available as open access since 2015 (see Figure 2).

\section{Rwanda, East Africa}

\section{Open Knowledge and Open Research: the Rwanda Experience}

East African countries still lag behind other African countries in terms of open knowledge due to reasons such as a lack of open access platforms, lack of awareness and readiness of some researchers to publish in open access outlets (Dulle; EIFL). Regionally, Rwanda is moving more slowly than its counterparts Kenya, Tanzania and Uganda in the adoption of open access and institutional repositories. According to the Registry of Open Access Repositories (University of Southampton) the only listed institutional repository in Rwanda is at the University of Rwanda. According to Kakai, Musoke, and Okello-Obura (2018), open access and repositories are still in the intermediate stages, with libraries taking the lead in promoting the two concepts.

According to the Rwandan Higher Education Council (HEC), as of March 2019 Rwanda had two accredited public institutions of higher learning and 29 accredited private institutions of higher learning. All these institutions have libraries and/or information centres that act as a point of call for information dissemination. Wakhungu Olaka notes that libraries and librarianship have had a difficult growth in Rwanda. This has affected the quality of library services and even curtailed the vision and missions of many libraries.

Public institutions of higher learning in Rwanda operate public libraries. However, these libraries do not advertise this fact (Anderson). This has had a profound impact on how the public accesses information. Private institutions of higher learning, due to their nature, provide access to information for a select clientele. This again hinders universal access to information. Gathoni et al. state that Rwanda, like most African countries, lacks both libraries and reading culture. Apart from university libraries, most institutional libraries have limited collections. The lack of a reading culture means that less emphasis is on developing libraries as centres of information access and information exchange.

In 2013, Rwanda enacted the Freedom to Information law making it at the time the 11th country in Africa to enact such a law. This law provided and still provides a framework for public institutions to undertake open access and knowledge sharing. Open knowledge and open research are key in Rwanda. The Global Open Data Index of 2015 showed Rwanda had the most government open data in Africa (Open Knowledge). This shows that from a government point of view open knowledge is key for the socioeconomic growth of the country. With the government giving great emphasis to open 
data and open knowledge, other public institutions have taken the cue and have started advocating for open knowledge and open research.

The Government of Rwanda has recognised that open learning can and should be used to increase the capacity for institutions of higher learning in Rwanda (Mukama). This is demonstrated by the implementation of an Open Distance Learning (ODL) policy within the Rwandan Vision 2020 Strategy. According to the Ministry of Education (2016), ODL is seen as a means of increasing access to education while at the same time increasing the dissemination of information. In other words, Rwanda has effectively seen open scholarship as a key component in its education sector. This has in effect pushed various public as well as private institutions of higher learning to adopt policies that encourage open scholarship.

\section{Open Access Policies: Overview of Universities. University of Rwanda (UR)}

In March 2015, the University of Rwanda published an open access policy and procedures document (University of Rwanda, 2015). The stated objective of this policy is to provide and improve wide access to scholarly and research output of UR as well as increase the dissemination and exchange of research output. The policy also encourages UR staff to engage in open knowledge by publishing their works through open access journals.

The policy also establishes a repository by which the research output of all UR staff shall be deposited. This repository shall operate under an open-access framework thus allowing easy and free dissemination of information. Under its open access publishing framework, UR prefers the Green Open Access framework which allows the authors to self-archive in open access institutional repositories after a specified time. However, the university states it will strive to assist authors who wish to use the Gold Open Access framework. Figure 4 shows the percentages of types of open access for items with DOIs, with marked growth in green and gold (OA and hybrid journals) output since 2014.

Figure 4: University of Rwanda: Percentages of open access research output (items with DOIs), 2004-2018

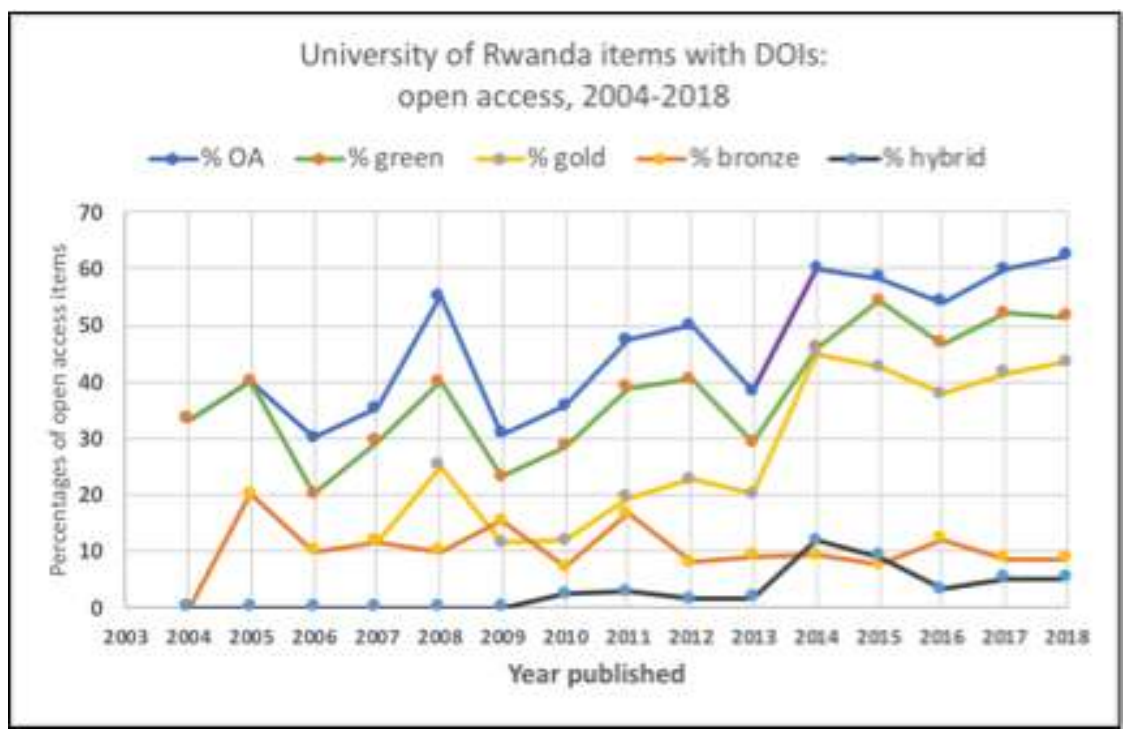

(Data sources: Microsoft Academic, Scopus, Web of Science. Analysis and image, COKI, January 2020) 

access policy that generally addresses access to research output, it does not address the issues that relate to disseminating the said information. The policy seems to encourage the public to the university while keeping silent on how the university can interact with the public.

31 A study by Nsanzabaganwa et al. shows research dissemination by medical students at UR is quite low. According to this study, one of the contributing factors to low research dissemination is the lack of a guiding policy on how students should disseminate their research. This means that students do not have a framework by which they can undertake any information transfer with the public.

However, a concept paper (University of Rwanda 2019) has been developed to address this issue. One of the six objectives this concept paper addresses is the issue of research dissemination. It proposes strengthening the capacity of UR for innovation and more critically information transfer between it and the public and private sector in Rwanda and regionally.

\section{University of Global Health Equity (UGHE)}

global health workers to bridge inequities that exist within the health sector. Key to this vision and aim is research and research dissemination more so within the community.

lst being a new university accredited in 2019, UGHE has been on the front line in championing open access. Open access at the university is seen as a key strategy in the exchange and transfer of information to the community. Towards this end, UGHE has placed Community Based Education (CBE) as a key component for information dissemination. Within the CBE, UGHE has employed Community-Based Participatory Research (CBPR) as a means of being an open knowledge institution.

According to Horowitz, Robinson, and Seifer, CBPR is an approach that involves equitably sharing researchers and those directly affected by and knowledgeable about the local circumstances that research wishes to address. This approach embraces the community and has been seen as increasing the effectiveness of research dissemination (Wallerstein and Duran).

While CBPR has proved to be an effective method of research information dissemination, UGHE has recognized the importance of using other strategies to enhance its openness. Towards this end, the University is currently in the process of drafting an Open Access Policy which will see the whole process anchored within the institution's regulations. The draft policy will address issues that hinder access and dissemination of information.

\section{South Africa}

Open access in institutional repositories and dissemination of research output in South Africa

37 As in the rest of the world, open access in South Africa has been supported since 2005 by Universities and Research Councils through either Gold, Green or both forms of 
open access. In many of these institutions, it remains essentially a bottom-up movement, driven by stakeholders such as research institutes and libraries. Therefore, mostly soft measures have been implemented to promote open access.

The first policy moves by institutions and the National Research Foundation (NRF) were concerned with open access to research publications and associated data. In 2015, the National Research Foundation, a key national funder, issued a statement on open access publications, requiring authors of research papers generated from research either fully or partially funded by NRF to deposit author accepted manuscripts (AAM) or final PDFs into an Institutional Repository, with an embargo period of no more than 12 months (National Research Foundation). The statement also declared that data supporting publications should be deposited in an accredited open access data repository.

Open access through the green route has been adopted by most institutions. Challenging the very high cost of subscription journals and to democratize knowledge, the gold route has been pursued through the provision of open access journal publication. The proposed transition to full-scale gold open access has received considerable attention, but questions regarding the scalability of the deal, mainly due to Article Processing Charges, remain to be answered. Open access to research data is even less developed across institutions than open access to research publications, with a few institutions and isolated researchers very proactively driving the debate forward.

The Academy of Science of South Africa (ASSAf) has become a key player in delivering open access in South Africa. It has national support for its SciELO South Africa open access journal programme, adopted in 2006. This provides an open platform for hosting scholarly journals and publication support through the Open Journal Systems online publishing programme, and a systematic peer review process for existing scholarly journals to build up a strong, quality South African scholarly journal system with wide local and international reach. SciELO South Africa collaborates with the important Latin American network SciELO, based in Brazil, which assisted with the adoption of open access publishing, evident in the results of two studies (ASSAf, 2006, 2019).

In the latest global developments in research communication, a more radical agenda is emerging through the promotion of open and collaborative science. This promises to go even further in ensuring more active participation by South African researchers in global networks. The European Commission has launched the latest phase of its ambitious Horizon 2020 programme, in which the latest round of priorities for the next phase include an open science vision of integrated research publication, open and collaborative science and innovation (Gray).

42 Europe and the United States are tightening their policies around full open access, of which Plan S is an example, supported by major funding agencies such as the Wellcome Trust, Bill and Melinda Gates Foundation. The introduction of such policies and the uptake thereof might differ from country to country. This is also true for the South Africa National System of Innovation in establishing its own position regarding Open Science policies and Plan S uptake.

43 During 2019, the South African Department of Science and Technology released its new White Paper on Science, Technology and Innovation to take the country forward as a leading African knowledge provider aligned with $21^{\text {st }}$ century technology and $21^{\text {st }}$ century thinking (Department of Science and Technology). One of the main thrusts of 
the White Paper is how Open Science, which encompasses open access to scholarly publications, open data, open and collaborative research, all essentially relate to the democratization of knowledge.

As South Africa, through the Department of Science and Innovation, seeks policy directions for a $21^{\text {st }}$ century system, it is clear that it will be doing so against the background of a much-changed research policy environment. This environment in the $21^{\text {st }}$ century world is one in which openness in research communication, collaboration between countries in analyzing open online data, and the use of online networks to allow citizen science to help build scientific knowledge, are but some ways in which open science is being advanced.

To understand further the open knowledge landscape in South Africa we analysed public data from forty-six educational and research institutions in South Africa. This includes twenty-six public universities and universities of technology identified by the Department of Higher Education and Training, and twenty research institutes and councils identified through the GRID identifier website (Digital Science \& Research Solutions).

Twenty-nine institutions (24 universities and five research institutes) have institutional repositories providing open access to staff research publications and student theses.

South African universities host their own or share a repository. Twelve universities and two research institutions, including the National Research Foundation, display public policies or statements requiring or recommending open access publication or repository deposit of institutional research output. Citing the NRF statement and/or the 2003 Berlin Declaration on Open Access (Max Planck Gesellschaft) often appears to be a proxy for institutional policies, an indication of institutional commitment to open access. Signatories to the Berlin declaration include 17 universities and two research institutions. Four universities make funds available to support researchers publishing in open access. The funds subsidise or cover processing charges (APCs, BPCs) for publishing scholarly articles, conference papers, and books with open access publishers or on open access platforms, and may contribute towards membership fees with open access publishers. See Table 2.

Table 2. South Africa - Open access policies, Berlin signatories, Open access publishing funds, institutional repositories. $\mathrm{COKI}$ analysis

\begin{tabular}{|l|l|l|l|l|l|}
\hline $\begin{array}{l}\text { Institution } \\
\text { type }\end{array}$ & $\begin{array}{l}\text { Number of } \\
\text { institutions }\end{array}$ & $\begin{array}{l}\text { OA Policy or } \\
\text { mandate }\end{array}$ & $\begin{array}{l}\text { Berlin } \\
\text { signatory }\end{array}$ & $\begin{array}{l}\text { OA } \\
\text { funds }\end{array}$ & $\begin{array}{l}\text { Institutional } \\
\text { Repository }\end{array}$ \\
\hline Universities & 26 & 12 & 17 & 4 & 24 \\
\hline $\begin{array}{l}\text { Research } \\
\text { institutions }\end{array}$ & 20 & 2 & 2 & 0 & 5 \\
\hline
\end{tabular}

Institutional repositories for the deposit of research publications, theses and dissertations appear to be well established among South African institutions, although some show small numbers of documents deposited.

Nine institutions (five universities and four research institutes) have publicly available research data management (RDM) or data curation policies. Eleven institutions (five 
universities and six research institutions) have publicly available data sharing policies or guidelines, often embedded within RDM policies and planning documents, library guides or annual reports. Eleven institutions have separate open data repositories: six universities and five research institutes, and several others include datasets in their institutional repository.

The growth of open access research output from 2000 to 2018 as a percentage of total research output through repositories and published journals for the 38 South African institutions included (those with available OA publication data) is shown in Figure 5.

Figure 5: Percentages of open access research output (items with DOIs) for 38 South African institutions, 2000-2018

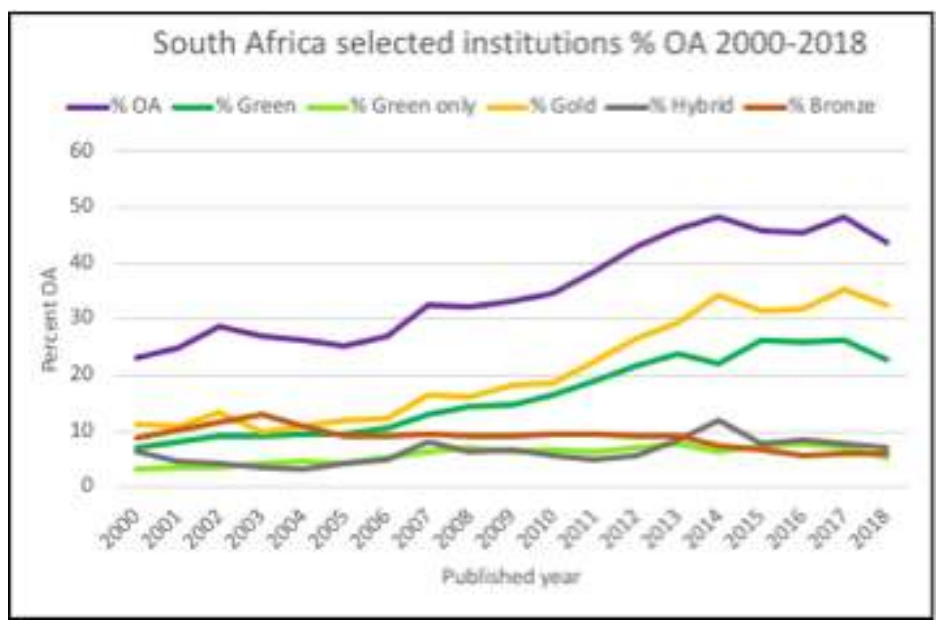

Analysis and image, COKI, October 2019)

(Data sources: Microsoft Academic, Scopus, Web of Science.

51 Total OA output reached $48 \%$ of published items with DOIs in 2014 and again in 2017. Gold OA (OA journals and hybrid OA) overtakes Green from 2013, likely a result of South Africa's collaboration with the SciELO network in 2006. Smaller percentages exist for Bronze OA and Hybrid OA. Green-only OA refers to open access output only archived in an institutional or subject repository.

The growth in the number of published research items from the South African institutions from 2000 to 2018 is substantial. Figure 6 illustrates the total number of items published with DOIs and the number of those available as open access. 
Figure 6: Published research items and numbers of open access items for 38 South African institutions, 2000-2018

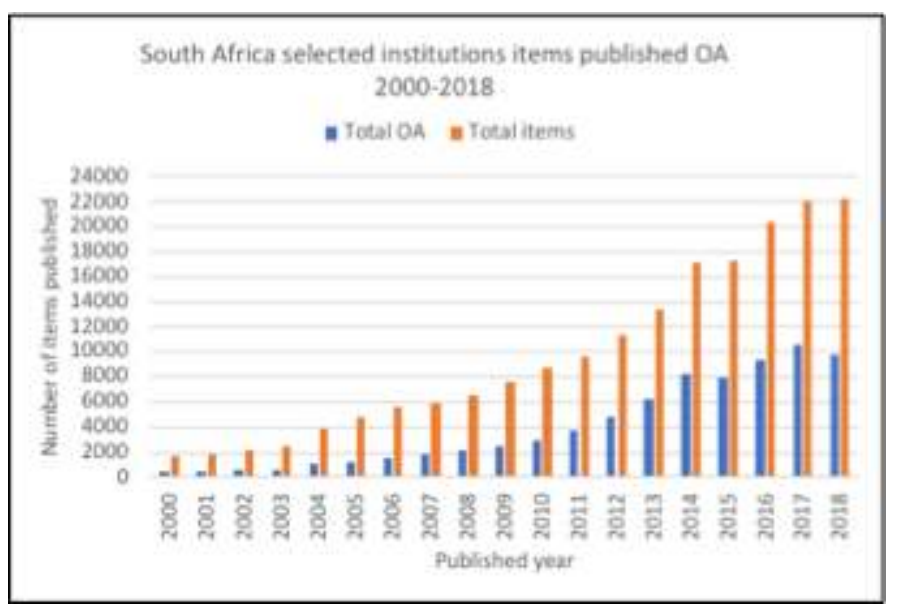

(Data sources: Microsoft Academic, Scopus, Web of Science Analysis and image, COKI, October 2019)

There are many issues that still need to be addressed to ensure that science in South Africa is changing from a closed system to an open and sharing one. Through the SA-EU Open Science Dialogue Report (2018) policy recommendations have been proposed and clustered into six themes: changes to policy and regulations, human resource development, financing, governance and metrics.

54 A start has certainly been made in South Africa to embrace openness, and the advocacy and actions that have taken place to make science more open are reaping results. South Africa is looking forward to being aligned and to taking the lead alongside its international counterparts with research communication, data sharing, and collaboration.

\section{Uganda, East Africa}

To understand the open knowledge landscape in Uganda, COKI analysed policy and research publication data from forty educational and research institutions, including nine public universities and twenty-six private educational institutes accredited by the Uganda National Council for Higher Education. Five research centres, councils and institutes and one regional universities forum were identified through the GRID identifier website (Digital Science \& Research Solutions).

We located no public policies or statements requiring or recommending open access publication or repository deposit of research output. One university is a signatory to the Berlin Declaration on Open Access (Max Planck Gesellschaft). There was no evidence of the provision of institutional funds to subsidise or support open access publishing. However, 17 institutions (15 universities and two research institutes) have institutional repositories, providing open access to research output. 
Table 3. Uganda: policies or mandates, OA publishing funds, Berlin signatories and institutional repositories, 2019

\begin{tabular}{|l|l|l|l|l|l|}
\hline Institution type & $\begin{array}{l}\text { Number of } \\
\text { institutions }\end{array}$ & $\begin{array}{l}\text { OA Policy or } \\
\text { mandate }\end{array}$ & $\begin{array}{l}\text { Berlin } \\
\text { signatory }\end{array}$ & $\begin{array}{l}\text { OA } \\
\text { funds }\end{array}$ & $\begin{array}{l}\text { Institutional } \\
\text { Repository }\end{array}$ \\
\hline Universities & 36 & 0 & 1 & 0 & 15 \\
\hline $\begin{array}{l}\text { Research } \\
\text { institutions }\end{array}$ & 4 & 0 & 0 & 0 & 2 \\
\hline
\end{tabular}

57 Although public policies were not identified, the total percentage of open access research output for the 16 institutions has grown since 2000, reaching 74 percent in 2017. Figure 7 illustrates this growth and the predominance of Green and Gold open access. The increase suggests an awareness among researchers about funder requirements, open publishing and knowledge sharing, supported by organisations such as EIFL and the International Network for the Availability of Scientific Publications working with the Consortium of Uganda University Libraries (EIFL; Kakai, Musoke, and Okello-Obura).

Figure 7: Percentage of open access research output with DOIs from 16 Ugandan institutions, 2000-2018

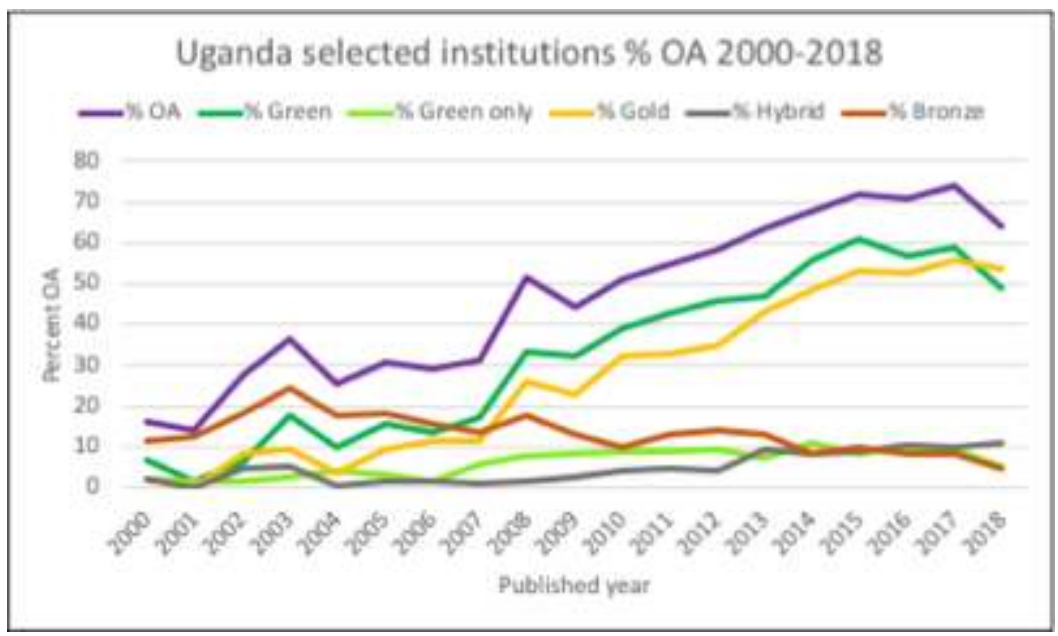

(Data sources: Microsoft Academic, Scopus, Web of Science Image and analysis COKI, October 2019)

The number of items output has also grown since 2000, and the relative number of items available as open access is substantial, as shown in Figure 8. However, some institutions have small numbers of research output, with substantial output from one university. 
Figure 8: Total research items with DOIs available as OA for 16 Ugandan institutions, 2000-2018

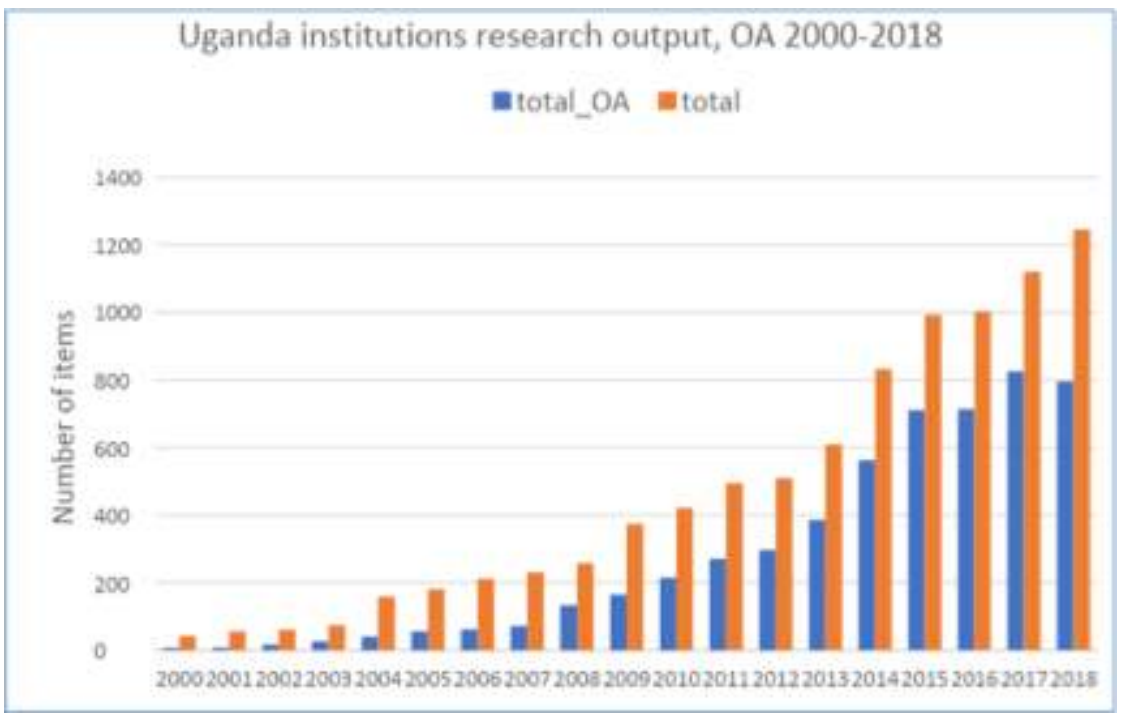

(Data sources: Microsoft Academic, Scopus, Web of Science Image and analysis COKI, October 2019)

The presence of institutional repositories for the deposit of research publications, theses and dissertations indicates the practice is well established in half the universities. Repositories are advertised on institutional websites, although ongoing advocacy and awareness-raising is recommended (Kakai, Musoke, and Okello-Obura).

\section{Conclusion}

This paper explores the varied and changing open knowledge institutional landscape in Ghana, Rwanda, South Africa and Uganda. Identifying and analysing open access research policies, practices and repositories, it expands on qualitative and bibliometric research into African output. Through our analysis of research output data, the strength of open access performance emerges, particularly the Gold and Green routes. This reflects the high performance of African institutions identified in the global context as shown in Figure 1. Gold appears to be overtaking Green in some countries, reflecting a greater awareness among researchers of open access journals (Kakai et al), funder mandates, and the growth of locally produced open access journals. This is discussed further in our forthcoming paper on evaluating institutional open access (Huang et al). Further analysis of the sources and discipline focus of Gold open access publications from African institutions will enrich our understanding of the burgeoning openness in this region.

61 This study contributes to understanding the landscape of African open knowledge performance, and illustrates how open access journals, policies, strategies and institutional repositories can facilitate the dissemination of research, including locally produced research, more widely and openly within Africa and globally. The analysis will assist research institutions and countries to understand, extend and build on the strengths and potential of their existing open knowledge practices. 


\section{BIBLIOGRAPHY}

Addo, Clement Prince. "How the Price of Bandwidth Can Be Cut in African Countries." The Conversation, 19 Dec. 2019, theconversation.com/how-the-price-of-bandwidth-can-be-cut-in-africancountries-128474.

Academy of Science of South Africa. Report on a Strategic Approach to Research Publishing in South Africa. Academy of Science of South Africa, 2006. DOI:10.17159/assaf/0038.

Academy of Science of South Africa (ASSAf). Twelve Years Later: Second ASSAf Report on Research Publishing In and From South Africa [2018]. Academy of Science of South Africa, 2019. DOI:10.17159/ assaf.2018/0030.

African Journals Online (AJOL). www.ajol.info/. Accessed 4 Jan. 2020.

Ahinon, Justin Sègbédji, \& Johanna Havemann. Open Science in Africa - Challenges, Opportunities and Perspectives. Nov. 2018, DOI:10.5281/zenodo.1492744 AfricaArXiv.

Anyaoku, E. N., et al. "Digital Preservation Practices in University Libraries: An Investigation of Institutional Repositories in Africa." Digital Library Perspectives, vol. 35, no. 1, 2019, pp. 41-64. DOI: 10.1108/DLP-10-2017-0041.

Anderson, Brian D. “A Survey of Law Libraries in Rwanda.” Law Library Journal, vol. 107, no. 2, Spring 2015, pp. 225-39.

Baker, Simon. "Are Research Links with the Developing World Still a One-Way Street?" Times Higher Education (THE), 2020, timeshighereducation.com/features/are-research-links-developingworld-still-one-way-street.

Bangani, Siviwe. "The History, Deployment, and Future of Institutional Repositories in Public Universities in South Africa." The Journal of Academic Librarianship, vol. 44, no. 1, Jan. 2018, pp. 3951. DOI:10.1016/j.acalib.2017.12.003.

Chan, Leslie. “Open Insights: An Interview with Leslie Chan.” Open Library of Humanities, 2018, openlibhums.org/news/314/.

Confraria, Hugo, \& Manuel Mira Godinho. "The Impact of African Science: A Bibliometric Analysis.” Scientometrics, vol. 102, no. 2, Feb. 2015, pp. 1241-68. DOI:10.1007/s11192-014-1463-8. Department of Higher Education and Training. n.d. Universities in South Africa, dhet.gov.za/ SiteAssets/New\%20site\%20Documents/Universities\%20in\%20South\%20Africa1.pdf

Department of Science and Technology. White Paper on Science, Technology and Innovation, 2019, dst.gov.za/index.php/legal-statutory/white-papers/2775-white-paper-on-science-technology-andinnovation.

Digital Science \& Research Solutions. GRID: Global Research Identifier Database. 2019, www.grid.ac/.

Dulle, F. W. An Analysis of Open Access Scholarly Communication in Tanzania Public Universities. University of South Africa, 2010.

Electronic Information for Libraries (EIFL). 2017 Annual Report / EIFL. 2017, eifl.net/annual-report/ 2017-annual-report\#block-views-annual-report-block-41.

Gathoni, Nasra, et al. "International Trends in Health Science Librarianship Part 14: East Africa (Kenya, Uganda, Rwanda).” Health Information \& Libraries Journal, vol. 32, no. 2, 2015, pp. 150-55. DOI:10.1111/hir.12103. 
Gray, Eve. “Open Access, Open Data, Open Science.” The Mail \& Guardian, 9 Dec. 2016, mg.co.za/ article/2016-12-09-00-open-access-open-data-open-science/.

Horowitz, Carol R. MD, et al. "Community-Based Participatory Research from the Margin to the Mainstream: Are Researchers Prepared?" Circulation, vol. 119, no. 19, May 2009, pp. 2633-42. DOI: 10.1161/CIRCULATIONAHA.107.729863.

Huang, Chun-Kai, et al. Evaluating Institutional Open Access Performance: Methodology, Challenges and Assessment. Mar. 2020. DOI: 10.5281/zenodo.3716263.

International African Institute. 2019. “African Digital Research Repositories.”, internationalafricaninstitute.org/repositories.phtml

Iyandemye, Jonathan, \& Marshall P. Thomas. "Low Income Countries Have the Highest Percentages of Open Access Publication: A Systematic Computational Analysis of the Biomedical Literature." Plos One, vol. 14, no. 7, July 2019, e0220229. DOI:10.1371/journal.pone.0220229.

Jisc Services. "Directory of Open Access Repositories - v2. Sherpa.” OpenDOAR, v2.sherpa.ac.uk/ opendoar/. Accessed 16 Jan. 2020.

Kakai, Miriam, et al. "Open Access Institutional Repositories in Universities in East Africa." Information and Learning Science, vol. 119, no. 11, Jan. 2018, pp. 667-81. DOI:10.1108/ILS-07-2018-0066. Lamptey, Richard, \& A. Corletey. "Enhancing Institutional Repositories (IR) in Ghana." Open Access to STM Information: Trends, Models and Strategies for Libraries, De Gruyter Saur, 2011.

Martin-Yeboah, Ebenezer, Anankyela Anaba Alemna, \& Emannuel Adjei. "Scholarly Communication via Institutional Repositories: A Ghanaian Perspective”, 2018. Library Philosophy and Practice; Lincoln, pp. 1-45.

Masaka, Dennis. “'Open Access' and the Fate of Knowledge from Africa: A Theoretical Discussion." The Journal of Negro Education, vol. 87, no. 4, 2018, pp. 359-74.

Max Planck Gesellschaft. Berlin Declaration on Open Access to Knowledge in the Sciences and Humanities, 2019, openaccess.mpg.de/319790/Signatories.

Morrison, Heather. "Dramatic Growth of Open Access 2019." Sustaining the Knowledge Commons / Soutenir Les Savoirs Communs, 3 Jan. 2020, sustainingknowledgecommons.org/2020/01/03/dramaticgrowth-of-open-access-2019/.

National Research Foundation. Statement on Open Access to research publications from the National Research Foundation (NRF)-funded research, 2015, https://www.nrf.ac.za/sites/default/files/documents/ oastatement_2015.pdf.

Nsanzabaganwa, Christian, et al. "Write-up and Dissemination of Undergraduate and Postgraduate Research at the University of Rwanda: A Cross-Sectional Study." The Pan African Medical Journal, vol. 32, Apr. 2019. DOI:10.11604/pamj.2019.32.164.18409.

Okoroma, Francisca Nwakaego. "Awareness, Knowledge and Attitude of Lecturers towards Institutional Repositories in University Libraries in Nigeria." Digital Library Perspectives; Bingley, vol. 34, no. 4, 2018, pp. 288-307.

Open Knowledge. “Global Open Data Index.” Open Data Index, 2015, 2015.index.okfn.org/place/.

Paterson, Mark. “Plan S - How Scholarship Is under Threat.” University World News, 28 Nov. 2019, universityworldnews.com/post.php?story= 2019112805442788.

Piron, Florence. Postcolonial Open Access. 2018. corpus.ulaval.ca/jspui/handle/20.500.11794/16178. 
Piwowar, Heather, et al. "The State of OA: A Large-Scale Analysis of the Prevalence and Impact of Open Access Articles." PeerJ, vol. 6, Feb. 2018, e4375. DOI:10.7717/peerj.4375.

Pretorius, Tyrone. “A Unique Approach Is Required When Ranking Africa's Universities.” The Conversation, 21 Aug. 2015, http://theconversation.com/a-unique-approach-is-required-when-rankingafricas-universities-46216.

Raju, Reggie. "Ubuntu: A Social Justice Pillar for Open Access in Sub Saharan Africa." Open Divide: Critical Studies on Open Access, Library Juice Press, 2018, pp. 157-68, DOI:10.5281/zenodo.120639.

Republic of Rwanda: Higher Education Council. 2020, hec.gov.rw/index.php?id=4.

Sooryamoorthy, Radhamany. "The Production of Science in Africa: An Analysis of Publications in the Science Disciplines, 2000-2015.” Scientometrics, vol. 115, no. 1, Apr. 2018, pp. 317-49. DOI: $10.1007 / \mathrm{s} 11192-018-2675-0$.

Springer Nature. “2019 Tables: Countries/Territories”. Nature Index. 2019. natureindex.com/annualtables/2019/country/all/regions-Africa.

Tambo, Ernest, et al. "Can Free Open Access Resources Strengthen Knowledge-Based Emerging Public Health Priorities, Policies and Programs in Africa?" F1000Research, vol. 5, May 2016, pp. 853. DOI: $10.12688 /$ f1000research.8662.1.

Silva, Jaime A. Teixeira da, et al. "Africa's Challenges in the OA Movement: Risks and Possibilities.” Online Information Review, Aug. 2019. DOI:10.1108/OIR-04-2018-0152.

The SA-EU Open Science Dialogue: SA-EU Open Science Dialogue Report. 2018, drive.google.com/drive/ folders/0B6w8fGuczhXqMFpLbHVEQ2JPV1U.

Twine, Rhian, et al. "Assessing the Effectiveness of a Longitudinal Knowledge Dissemination Intervention: Sharing Research Findings in Rural South Africa." Gateways: International Journal of Community Research \& Engagement, vol. 10, June 2017, pp. 143-63. DOI: 10.5130/ijcre.v10i1.5111.

University of Rwanda. Open access policy and procedures. 2015. ur.ac.rw/documents/ OPEN\%20ACCESS\%20POLICY_AND\%20PROCEDURE S.pdf.

University of Southampton. Registry of Open Access Repositories. n.d., roar.eprints.org/.

Wallerstein, Nina, \& Bonnie Duran. "Community-Based Participatory Research Contributions to Intervention Research: The Intersection of Science and Practice to Improve Health Equity." American Journal of Public Health, vol. 100 Suppl 1, 2010, pp. S40-46.

\section{ABSTRACTS}

This paper discusses research undertaken by the Curtin Open Knowledge Initiative (COKI) and participants during and following an Open Knowledge international workshop held in Mauritius in September 2019. The workshop brought together key experts to explore the role of open knowledge in the creation of equitable and inclusive global knowledge landscapes. This paper explores the role of open access and institutional repositories in knowledge sharing and the dissemination of research output from higher education and research institutions within the African continent. The paper reviews the landscape of research output from the African continent; analyses open access research output, overviews of institutional knowledge sharing positions and the dissemination of research output from Ghana, Rwanda, South Africa and Uganda. 
INDEX

Keywords: open knowledge, research output, Africa, institutional repositories

\section{AUTHORS}

\section{KATIE WILSON}

Curtin University

katie.wilson@curtin.edu.au

(corresponding author)

\section{ANTHONY KIUNA}

University of Global Health Equity

\section{RICHARD LAMPTEY}

Kwame Nkrumah University of Science and Technology

\section{SUSAN VELDSMAN}

Academy of Sciences in South Africa

\section{LUCY MONTGOMERY}

Curtin University

\section{CAMERON NEYLON}

Curtin University

RICHARD HOSKING

Curtin University

CHUN-KAI (KARL) HUANG

Curtin University

ALKIM OZAYGEN

Curtin University 